\title{
The Development of Connective Action during Social Movements on Social Media
}

\author{
MILAD MIRBABAIE, Faculty of Business Studies and Economics, University of Bremen, \\ Bremen, Germany \\ FELIX BRÜNKER, MAGDALENA WISCHNEWSKI, and JUDITH MEINERT, Department of \\ Computer Science and Applied Cognitive Science, University of Duisburg-Essen, Duisburg, NRW, Germany
}

In recent years, the development of information communication technologies, such as social media, has changed the way people communicate and engage in social movements. While conventional movements were fought in the streets, social media has enabled movements to take place online. In this article, we aim to investigate the role of social media during social movements that evolve online under the scope of the theory of connective action. Specifically, we examined Twitter communication during the \#metoo debate. To this end, we examined two datasets (2017 and 2019) and combined methods from social media analytics to identify influential users, with a manual content analysis to classify influential users into roles. Likewise, a manual classification found distinct communication categories. Through regression analysis, we were able to gage the individual contribution of these categories and roles based on the retweet probability. This study introduces for the first time the terms of connective action starters and maintainers.

\section{CCS Concepts: • Applied computing $\rightarrow$ Sociology; • Information systems;}

Additional Key Words and Phrases: Connective action, social media, social movements, Twitter

\section{ACM Reference format:}

Milad Mirbabaie, Felix Brünker, Magdalena Wischnewski, and Judith Meinert. 2020. The Development of Connective Action during Social Movements on Social Media. ACM Trans. Soc. Comput. 4, 1, Article 3 (April 2021), 21 pages.

https://doi.org/10.1145/3446981

\section{INTRODUCTION}

Over the past few years, social media has come to have a wide use in social movements. High connectedness, fast information diffusion, and lower individual costs are some of the reasons why a shift to the online sphere has been observed [15]. One way that this has been studied is through hashtag activism, which is defined as an approach "to raise awareness of an issue and encourage

This work was supported by the Deutsche Forschungsgemeinschaft (DFG) under Grant No. GRK 2167, Research Training Group "User-Centred Social Media." Furthermore, this project has received funding from the European Union's Horizon 2020 research and innovation programme under the Marie Skłodowska Curie Grant No. 823866.

Authors' addresses: M. Mirbabaie, Faculty of Business Studies and Economics, University of Bremen, Enrique-SchmidtStraße 1, 28359, Bremen, Germany; email: milad.mirbabaie@uni-bremen.de; F. Brunker, M. Wischnewski, and J. Meinert, Department of Computer Science and Applied Cognitive Science, University of Duisburg-Essen, Forsthausweg 2, 47057, Duisburg, Germany; emails: \{felix.bruenker, magdalena.wischnewski, judith.meinert\}@uni-due.de.

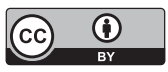

This work is licensed under a Creative Commons Attribution International 4.0 License.

(C) 2020 Copyright held by the owner/author(s).

2469-7818/2020/04-ART3

https://doi.org/10.1145/3446981 
debate" $[15,53]$ via the use of hashtags on social media. While hashtag activism and the way it is structured is a thought-provoking field in itself, we are more generally interested in who participates in these movements and what is shared by whom. Previous studies have already investigated content communication through social media in social movements [52], differences in communication patterns between two different social media sites [29], and the role of specific actors within these movements [55]. However, these pieces have so far not been put together. Less is known about the influence on the retweet probability of specific content that is shared by specific user groups [14]. Yet, to broaden the understanding of social movements on social media, it is crucial to understand the dynamics of communication among distinct groups participating in a social movement on social media [36]. To this end, the theory of connective action may deliver explanations about the origin and development of these social movements [5]. Connective action describes how loosely connected actors make use of technological platforms such as social media. It tackles the changes in shared forms of activism due to the enforcement of social media venues. Those led to reduced hierarchies in terms of organization and leadership of movements and looser connections among participants, although all of them contribute to a shared goal [5]. A discriminating characteristic of connective action marks the use of social media as fertile ground for communication and activation to take part [28].

We therefore examined one recent example of such a social movement, that is, the \#metoo movement. We investigated which kinds of user roles were involved in sharing and publishing tweets related to the \#metoo hashtag during the period from September 30, 2017, to November 30, 2017, as well as from May 01, 2019, to May 30, 2019. Additionally, we were not only interested in the users themselves but also in the content they shared. Therefore, we present findings on the following research questions:

RQ1: How do influential roles participate over the course of an online social movement on Twitter?

RQ2: How do they contribute to connective action over the course of an online social movement?

Answering these RQs will uncover influential roles and how they contribute to online social movements. In this context, we will extend the body of knowledge about the theory of connective action by reflecting on these roles from the perspective of connection action. Thus, this study will expand the understanding of the theory of connective action by providing novel insights about participating roles over the long-term course of an online social movement. Furthermore, the findings may support actors, such as Non Governmental Organizations (NGOs), activists, or governmental institutions, by providing knowledge on the understanding of how an online social movement is formed and evolves over the years. Considering these findings may help to better organize and understand loosely connected actors participating in the movement.

To answer the research questions, as a first step, we collected tweets based on relevant keywords. Based on the tracked data, we conducted a social network analysis [33, 35, 48] to identify influential users participating in the \#metoo debate during the examined time period and to assess underlying structures. Subsequently, we undertook a comprehensive manual content analysis [30] to classify the identified users into roles and then categorized the shared tweets into explicit content categories. In this research, we understand roles as specific user groups in accordance with Stieglitz et al. [49]. Thus, we examined which content was published by the top 300 power users of each dataset and which information of the \#metoo tweets was retweeted the most. Furthermore, we conducted sentiment analyses and a negative binomial regression to investigate factors influencing the spread of tweets. 
We expected that the identified roles altered their sharing behavior and, consequently, influenced the movement in different ways. We subsidized deeper insights into the specific case of \#metoo and generated a continuative understanding of how social media activism functions, concerning the different roles and their impact on connective action. Ultimately, we intended to increase our understanding of the contributions and potential but also possible downsides of social media use in social movements.

This study is structured as follows: First, we present an overview of the status quo of the literature about social movements in social media and introduce the theory of connective action. Second, we outline a summary of our research design. Subsequently, we present the findings of the examined \#metoo case. Last, we provide a conclusion and the outlook for further research.

\section{BACKGROUND}

\subsection{Social Movements in Social Media}

The development of Information Communication Technologies has changed the involvement of users in social media and online communities. Previous studies have shown that this happened via lowering individual costs of participating, increasing general accessibility to information [31], fostering connectivity between users [19], and creating a platform where users can generate content themselves.

This is not only reflected on the individual level but by affected social movements as well. In contrast to more organized offline social movements where individuals remain mostly passive, social movements on social media enable individuals to move from this passive state of participation to self-organized participation [27]. Organization and coordination rely much more on a personalized expression of identity, communication, and sharing than on more traditional forms like formal organizations and leaders [24]. Therefore, social movements have become much more self-organized and leaderless [25]. On the individual level, social media have enabled people to make informed decisions about their participation in general, while simultaneously increasing the chances that people participate [31] and facilitating the coordination of the protest [25].

With this in mind, it does not come as a surprise that social media can work, indeed, as a catalyst of a movement's success and that it facilitates information spread [12]. Taking this further, it was claimed that more and more social movements have become successful because of social media. Examples of such social media enabled movements are the Arab Spring [43], Occupy Wall Street in the US [22, 24], Los Indignados in Spain [54], and the \#YoSoy132 movement in Mexico [18]. Although these protests were founded offline, they are no longer only fought in the streets but also online. In agreement with the aforementioned features of social media, it was found that these can contribute to a movement's success both online and offline [3]. This new development came, however, with some costs. Phrases such as keyboard warrior or slacktivism suggest that, although participation in general seemed high, actual identification with a movement can still be low.

We suggest that the \#metoo debate brought something new into play again: The movement was initiated online and only eventually affected offline events (for a more detailed account, see Section 3.1). With this change of direction, namely from the online to the offline world, the central role of social media became even more evident. To understand the hows and whys of this change, we propose, with this study, to start looking at participating individuals and their online behavior.

\subsection{User Behavior on Twitter and Its Impact on Social Movements}

Social movements, whether online or offline, can be broken down into individuals' actions. To investigate a social movement, it is, therefore, important to understand how individuals behave on the respective platforms. For the case of \#metoo, we, accordingly, reflected on user behavior within the Twitter sphere. 
Through the opportunity for real-time sharing, Twitter is one of the most popular ways to spread information among a wide audience, impact a public discourse in society, and engage users in social discussions $[20,39,50]$. One recent study that examined three different movements (Occupy Wall Street, Indignados, and Aganaktismenoi) from three different countries found that Twitter indeed helped to popularize the cause and broaden the call for the public to engage [52].

In addition to that, Manikonda et al. [29] found reason to believe that user behavior between different social media platforms varied and could possibly alter a movement's development. While, during the \#metoo movement, Reddit users were more likely to share details of their own stories, Twitter users focused on being engaged with the online community and supported victims by posting hashtags and sharing news, URLs, or articles, and, most importantly, they encouraged others to engage in the (online) social movement [29]. Besides that, Twitter users also shared their stories but by focusing on the point that they were being harassed without sharing lots of details [29]. Concerning the use of hashtags, one exceptional example for its use in social movements on social media came from the Black Lives Matter debate. Hashtag use not only fostered public attention but also helped to connect individual people involved in the movement [7].

Likewise, it is crucial to differentiate users concerning their general impact on social networks $[9,32]$. For example, users with a higher social status provide information that is then spread by lower status users within a social network [8]. Therefore, celebrities are more likely, first, to spread information and, second, to be retweeted. Alongside celebrities, it was found that posts from other highly followed users, like leftists, activists, or bloggers, are more likely to be retweeted [45]. Concerning not only the impact of specific users but also the content, recent research found evidence for a difference in what type of content is posted by whom. For example, calls for action are rather rare and are mostly tweeted by activists [52].

Moreover, studies examining predictors of retweet probability on social media identified tweet features that increase the probability, for instance, specific hashtags, the usage of URLs, and content characteristics [50]. The special focus on retweet probability can be justified, because it was found that Twitter's retweet functionality was a central key mechanism for information diffusion on this platform $[8,34]$. Thus, retweeting others takes a central role in the context of analyzing influential online communication [47]. Besides, these features, especially the usage of emotional and affective language, are regarded as a reason why some content is more likely to be retweeted than others. Positive as well as negative emotions receive more feedback than others and can attract attention as well as cognitive involvement [46]. This leads to the conclusion that language affects the tendency to retweet some content more than less affective content.

Likewise, it was shown that specific content that people retweeted is inseparably linked to the construction of one's self-image and self-promotion [8]. In turn, people tend to retweet to spread information to new audiences as well as an act of friendship or loyalty by drawing attention to content [50]. Therefore, users might want to engage others in conversation and encourage them in social actions to eventually build a collective group identification [8].

Moreover, if we want to enrich the knowledge of how social media is deployed during social movements, then we need to ask different questions. For a better understanding of how people engage in online social movements and how this differs from the offline world, we need to know who participates on social media during social movements and how people create content and interact with the published information.

\section{THEORY OF CONNECTIVE AND COLLECTIVE ACTION}

Although individual behavior is worth investigating, in the past, social movements have been scrutinized under the logic of networked action, also called collective action. Overall, networks that 
reflect the logic of collective action are considered as distinct groups that network to bring members and connected participants into the action and to keep them engaged. This action emphasizes the problem of getting individuals to contribute to the collective undertaking. Characteristically, this includes seeking public goods like democratic reforms [5]. Furthermore, Olsen [40] pointed out that it is rational for individuals to not contribute, although everyone agreed that they would all be better off if everyone did. Overall, networks that reflect the logic of collective action are considered as distinct groups that network to bring members and connected participants into the action and to make them stay there.

The theory of collective action provides an answer to the general question of why people get involved in collaborations with others by explaining that people act in a collective manner with the purpose of achieving a shared goal $[40,41]$. This addresses goals mainly in the form of public goods [6], those from which many members of society can profit (even those individuals who did not take part in the collective action). This refers to diverse actions ranging "from neighborhood associations to community organizations and urban coalitions to trade agreements, defensive alliances, and collaborative initiatives on national and international scales.” [17:185].

In that sense, collective action refers to loosely connected groups of individuals that are engaging in an organized protest (in the case that they are against something) or a campaign (in the case that they are promoting something). It has to be considered that these actions are normally not professional but rather organized by a layperson [5]. These groups can be formally described by the number of participants, the heterogeneity of the group, and the relevance of the goal (e.g., for all members of the group, a subgroup, the entire society, etc.) [42]. Through the shared goal, collective actions are said to go along with a group identification. Traditionally, the theory of collective action is independent from media or social media usage and describes offline scenarios that are strongly and formally organized with stronger ties between the actors [28].

In contrast to this more traditional logic of action, the logic of connective action is based on the idea of digital media functioning as organizing agents. Whereas collective action networks have a strong organizational coordination of action, traditional organizations are either absent or only loosely responsible for the coordination in connective action.

In contrast, connective action is based more on the use of information technologies and engaged in digitally networked action [5], which leads to weaker ties in the network of participants. Moreover, participation in digitally mediated social networks becomes self-motivating, because self-produced content is shared with others and recognized by them. In turn, others will repeat these sharing activities [5].

With these interpersonal networks being enabled by technology platforms, the resulting action can be similar to collective action but without the importance of formal organizations or the transformation of social identification. This reveals a different economic and psychological logic, which is co-production and sharing based on personalized expression. Through these easily spreadable personal action frames and digital technology, action networks characterized by connective action can be scaled up quickly. One example of how the theory of connective action has been applied to social movements is the Occupy Wall Street protest, which spread to over 80 countries and 900 cities in only a month $[4,5]$.

In this context, two indicators may identify digitally networked action events [16]. The first indicator is that a large number of participants are mobilized by online social media. The second one is that just a small number of participants are members of staging organizations. For this investigation, we place \#metoo within the framework of connective action as the typical characteristics were present: communication was mostly digitally mediated, content was self-produced, people became mobilized online, and strong organizational coordination was missing. 


\section{RESEARCH DESIGN}

\subsection{Case Description}

In 2006, the social activist Tarana Burke introduced the phrase "Me Too" to empower women who have experienced sexual abuse. However, the grassroots campaign did not go viral until October 2017 when The New York Times published an article accusing the Hollywood producer Harvey Weinstein of sexual misconduct [23]. In response to the rising allegations, the actress Alyssa Milano tweeted, "If you have been sexually harassed or assaulted write 'me too' as a reply to this tweet." Following this, the hashtag spread virally: It was used more than 500,000 times on Twitter in 24 hours and evolved into a social movement against sexual harassment and sexual assault, especially in the workplace. Inspired by Milano's tweet, users on Twitter and other social media platforms shared, commented on, and discussed their own personal experiences related to sexual misconduct. The hashtag was seen and shared not only on Twitter, which even dedicated the hashtag its own icon, but also through other social media platforms like Facebook and Reddit, as well as in various online news articles. Although the hashtag movement originated in the United States, it gained worldwide recognition. Within days it spread to countries all over the world, leading to tangible consequences in the physical world, such as marches in the streets [21]. Two years later, \#metoo is still highly discussed and accompanied by ongoing court proceedings.

\subsection{Data Collection and Analysis}

For our empirical analysis, we collected tweets regarding the \#metoo debate in 2017 and 2019 from Twitter. For the first dataset, we examined two months of online communication regarding the origin of the movement, from September 30 (22:00 UTC), 2017, to November 30 (23:59 UTC), 2017. For the second dataset, we gathered one month of online communication, which was not influenced by a specific event on the \#metoo agenda, from May 01 (00:00 UTC), 2019, to May 30 (23:59 UTC), 2019. Twitter has been proven to be a substantial tool for information exchange during social movements [38], as one of the features of Twitter is the function of real-time interaction by retweeting others $[20,39]$. By conducting an exploratory prior analysis on trending hashtags and topics, specific hashtags were shown to be most frequently used during the debate, covering the majority of related online communication. Thus, we collected tweets containing at least one of the following hashtags: \#metoo, \#meninists, \#antifeminism, \#norightsforwomen, \#weinstein, \#sexism, \#menot, \#CN_sexism, \#gender, and \#itwasme. Due to its origin in the United States, we focused on Twitter communication in English. The fundamental data for this study were collected through the Search $\mathrm{API}^{2}$ of Twitter with a self-developed Java crawler, using the Twitter4J library. ${ }^{3}$ The gathered data were stored in a MySQL database, from where we conducted further analysis steps.

To identify the participants and their roles in the communication, we focused on power users and used social network analysis methods in combination with manual content analysis to categorize the participants into roles [48]. Power users can be classified as participants who receive the highest numbers of retweets within a network [39, 49]. To examine the majority of case-related Twitter communication, we analyzed the tweets of the top 300 power users by the in-degree of each dataset. To this end, we created a communication network based on Twitter data. The nodes (vertices) of our network are Twitter users and the edges are retweets; thus, the given network is a directed network. The edge weights are the number of retweets. The in-degree is the value of how much a node has been retweeted, whereas the out-degree describes the value of how much a node has retweeted itself. Since the data are represented in a directed network, the in-degree is also an

\footnotetext{
${ }^{1}$ https://twitter.com/Alyssa_Milano/status/919659438700670976/photo/1, last access: 2020-03-26.

${ }^{2}$ https://dev.twitter.com/rest/public/search, last access: March 26, 2020.

${ }^{3} \mathrm{http}: / /$ twitter4j.org, last access: 2020-03-26.
} 
indicator of the popularity of the retweeted tweet or the retweeted participant by quantifying the frequency of being retweeted. Additionally, we also calculated the overall follower count and the betweenness centrality value based on the directed network. The betweenness centrality represents the degree to which a node is in a position of brokerage by summing up the fractions of the shortest paths between other pairs of nodes that pass through it [11]. In total, we considered the communication of 600 accounts. The samples represented the most retweeted, and therefore, the most influential users during the examined time period as well as less retweeted accounts, which may have had a role other than influencing other people. Thus, the classification of active roles was based on the majority of the gathered Twitter communication as well as stronger and lesser influential users within the dataset. The long-tail users by in-degree were not considered for the role classification due to their small degree of influence within the network.

To this end, we classified the top 300 power users of each dataset into roles and performed a categorization technique based on the suggestions of Mayring [30]. We defined a category for every power user present and their three most retweeted tweets during the examined period. If the subsequent power user and its tweets did not match this category, then we defined a new one. The classification of the roles was based on the most salient cues of the profile and content. The coders could only assign an account to one role exclusively. This methodical step was conducted by three independent researchers. To identify power users and patterns between distinct roles within the network, we analyzed and visualized the graph given by the retweet network with the Gephi open source tool. The approach of social media analytics includes a set of methods to examine social media data through the stages of (1) discovery, (2) tracking, (3) preparation, and (4) analysis [48]. To produce the visualizations of the described directed network graphs, we ran the ForceAtlas2 layout algorithm. Subsequently, the Giant Component filter was applied to remove nodes that were not connected to the main network. Furthermore, the Degree Range filter was used to get a clear visualization of the network. The size of each node represents the number of retweets from a node. The color of the nodes represents the assigned role of the participants.

To further analyze the data on a content level, we conducted a manual content analysis of the communication of each of the top 300 power users. Overall, we regarded the 10 most retweeted tweets of each of the 600 gathered users. However, not every power user posted at least 10 tweets. Thus, we manually categorized a total sample of 2,010 tweets for the first dataset and 1,464 tweets for the second dataset into descriptive and content categories. Each individual tweet served as one unit of analysis. Due to the large number of tweets and their heterogeneous content, two complementary approaches were selected to best represent the material, namely descriptive and content-related categories (see the categorization plan). Following the procedure of Mayring [30], categories were developed, partly theoretically and partly empirically driven. Analysis based on descriptive information included the following categories: (1) the number of hashtags used, (2) the presence or absence of an URL to an external source, (3) the tweet contained media other than text, (4) the tweet was a retweet, and (5) the tweet contained an “@mention," whereas analysis based on content-related information included these categories: (1) the tweet contained a call for action (e.g., requesting, challenging, promoting, inviting, summoning someone to do something), (2) the tweet contained a testimony of sexual harassment (e.g., report, declaration, first-person experience), (3) the tweet included the sharing of an opinion (e.g., evaluation, appreciation, addition, analysis), and (4) the tweet contained reference to a third party (reporting on something/-one, direct and indirect quotes). Because tweets could vary between simple keywords and several sentences, it was decided that the categories were not mutually exclusive but that one tweet could be categorized within multiple categories.

Furthermore, the development of all the categories followed an iterative process. Three independent raters developed, tested, and were then trained to analyze the tweets. In three 
rounds of categorization, each rater categorized 50 tweets. To ensure the quality of the rating, after each round of categorization, inter-coder reliability was tested with Krippendorff's alpha and the KALPHA macro by Krippendorff and Hayes [26] for ordinal variables and multiple raters. According to the performance of a randomly chosen $10 \%$ of all the tweets, the intercoder reliability was high after the third round of categorization. As could be expected, Krippendorff's alpha for all descriptive categories reached 1, indicating coder agreement of $100 \%$. Content-related categories had medium to high alpha values: call for action $\alpha_{K}=.87$, testimony $\alpha_{K}=.90$, personal opinion $\alpha_{K}=.75$, and reference to a third party $\alpha_{K}=.69$.

To deepen the understanding of these categories, we conducted an automated sentiment analysis. Sentiment analysis provides a fine-grained computer-based analysis of written text about specific topics to reveal overall emotional orientation and its intensity [46]. To this end, we used the SentiStrength tool to analyze the emotionality (positive and negative proportion) of the tweets [51]. Recent sentiment analysis algorithms have been proven successful in classifying the emotionality of short-text messages, considering additional linguistic rules for amplification, boosting, emoticons, typos, or negotiations $[45,48,51]$. SentiStrength classifies the text in terms of positive emotions on a scale of 1 to 5 and regarding negative emotions on a scale of -1 to -5 . In this context, the tool gives each tweet a positive and a negative score. To better understand the tweets of identified roles, we computed the polarity of a tweet as well as the overall sentiment load [46].

To gain a better understanding of how specific categories contributed to the spread of a tweet as well as how the different roles shape the sharing process, we conducted negative binomial regressions for both datasets (for that of 2017 as well as that of 2019). The spread of a tweet was operationalized by a count variable of retweets. Since this dependent variable was represented by nonnegative count data with a variance larger than its mean, we conducted negative binomial regressions to adjust for overdispersion. In addition to the dummy-coded (DC) categories (call for action, testimony, sharing of personal information, and reference), we added, as predictors in our model, the following descriptive variables: (1) number of hashtags, (2) URL use in tweet (DC), (3) media use in tweet (DC), (4) retweet (DC), and (5) @mention use in tweet (DC). To gage the contribution of emotional language, we included the results of the sentiment analysis as two separate predictors (positive and negative sentiment). To assess the contribution of the different roles, we included the results of the coding process as a predictor into the regression analysis. Finally, we also included a word count variable to control for tweet length.

\section{RESEARCH FINDINGS}

\subsection{Participating Roles in Social Movements on Twitter}

The 2017 dataset consisted of 959,128 tweets and retweets by 609,169 accounts. The diameter of the extracted network was 32, whereas the average path length was 10.40 . Furthermore, the network consisted of $97.51 \%$ nodes and $93.75 \%$ edges after filtering with the Giant Component filter. The 2019 dataset consisted of 93,927 tweets and retweets by 83,993 accounts. The diameter of the extracted network was 27, whereas the average path length was 9.35. Furthermore, the network consisted of $80.95 \%$ nodes and $87.92 \%$ edges after filtering with the Giant Component filter.

Table 1 shows the descriptive network characteristics of the analyzed networks. To filter the data of the most influential accounts during the examined period, we calculated each node's in-degree.

Therefore, we identified the power users in the social movement. As a procedural step, we created two network graphs, each containing the top 300 power users and, by doing so, displayed possible relationships between the most influential roles within the network. Furthermore, Figure 1 shows a comparison between the most influential (sized by in-degree) roles within the top 300 power users of each dataset during the examined periods. 
Table 1. Descriptive Network Metrics

\begin{tabular}{|l|c|c|c|c|c|c|}
\hline & \multicolumn{3}{|c|}{ 2017 Dataset } & \multicolumn{3}{c|}{ 2019 Dataset } \\
\hline Metric & In-degree & Out-degree & Degree & In-degree & Out-degree & Degree \\
\hline Min & 0 & 0 & 1 & 0 & 0 & 1 \\
\hline Max & 48,885 & 1,289 & 48,885 & 11,113 & 814 & 11,113 \\
\hline
\end{tabular}
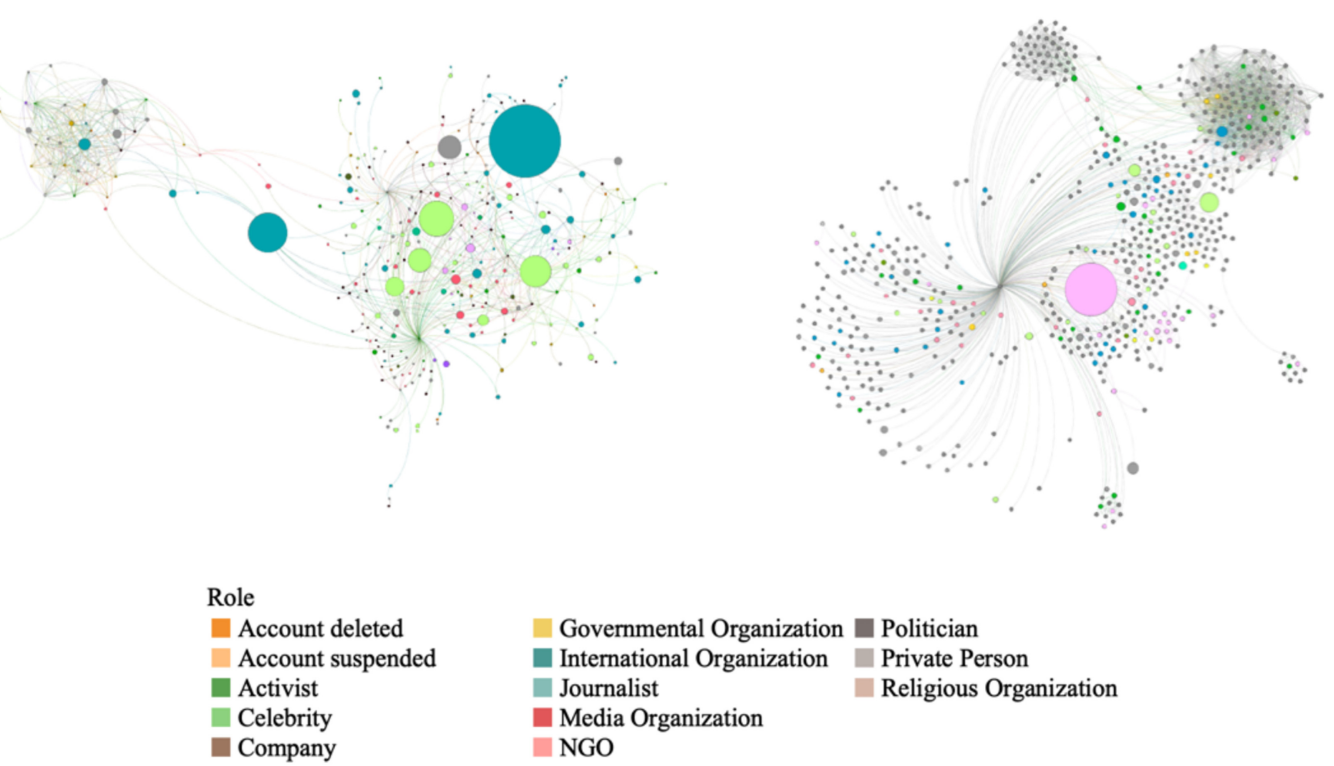

Fig. 1. Visualizations of the directed networks of each dataset (2017 left, 2019 right).

Subsequently, we created a sample of the top 300 power users during the examined time periods. To classify the identified power users into roles, we extracted three tweets per account. In total, we manually analyzed the content of 1,800 tweets and 600 accounts. Following the categorization technique based on Mayring [30], we defined a category for every account present. If the tweets and profile information of the subsequent account did not match a category, then we defined a new role category. This methodical step involved three independent researchers who came to a mutual agreement and a Krippendorff's alpha of 0.898 , signaling inter-coder reliability [26]. Table 2 shows the distribution of the identified roles in both analyzed datasets.

To further quantify the identified roles, Table 3 shows distinct metrics that are computed based on the directed networks of each dataset. The table displays the mean of the metrics in-degree, outdegree, number of unique modularity classed, eigenvector centrality, and betweenness centrality. Roles with a high eigenvector centrality are connected to valuable other roles within the network. Roles with a high betweenness centrality have the function of information brokerage and information transmitting.

\subsection{Behavior of Participating Roles in Social Movements on Twitter}

This section presents the findings of the manual content analysis regarding the dynamics of participating roles during the \#metoo debate. The findings show to what extent the identified roles differ among the descriptive and content categories. First, we present the descriptive 
Table 2. Identified Roles

\begin{tabular}{|c|c|c|c|}
\hline Role & Dataset 2017 & Dataset 2019 & Example \\
\hline Private Person & $22.66 \%$ & $35.54 \%$ & ordinary citizens or civilians \\
\hline Journalist & $16.68 \%$ & $11.14 \%$ & private and public accounts of journalists \\
\hline $\begin{array}{l}\text { Media } \\
\text { Organization }\end{array}$ & $17.03 \%$ & $9.64 \%$ & $\begin{array}{l}\text { newspaper and TV, like CNN, } \\
\text { Washington Post }\end{array}$ \\
\hline Activist & $11.35 \%$ & $13.74 \%$ & public declared (social) activist \\
\hline Celebrity & $10.41 \%$ & $5.33 \%$ & $\begin{array}{l}\text { public figures such as artists or } \\
\text { musicians }\end{array}$ \\
\hline Politician & $3.09 \%$ & $1.16 \%$ & $\begin{array}{l}\text { politicians such as Donald Trump or } \\
\text { Hillary Clinton }\end{array}$ \\
\hline NGO & $3.64 \%$ & $14.49 \%$ & $\begin{array}{l}\text { e.g., accounts of Amnesty International } \\
\text { or WWF }\end{array}$ \\
\hline $\begin{array}{l}\text { International } \\
\text { Organization } \\
\end{array}$ & $1.49 \%$ & $0.68 \%$ & $\begin{array}{l}\text { e.g., accounts of the United Nations or } \\
\text { NATO }\end{array}$ \\
\hline Company & $0.70 \%$ & $0.68 \%$ & $\begin{array}{l}\text { accounts of companies such as Amazon } \\
\text { or Apple }\end{array}$ \\
\hline $\begin{array}{l}\text { Governmental } \\
\text { Organization }\end{array}$ & $0.30 \%$ & $2.19 \%$ & $\begin{array}{l}\text { accounts hosted by the government like } \\
\text { the White House }\end{array}$ \\
\hline $\begin{array}{l}\text { Account } \\
\text { suspended }\end{array}$ & $5.98 \%$ & $4.24 \%$ & users suspended by Twitter \\
\hline Account deleted & $3.74 \%$ & $1.03 \%$ & accounts deleted by the user \\
\hline Social Bot & $2.89 \%$ & $0 \%$ & $\begin{array}{l}\text { artificial accounts that try to act like } \\
\text { humans }\end{array}$ \\
\hline
\end{tabular}

Table 3. SNA Measures of the Identified Roles

\begin{tabular}{|c|c|c|c|c|c|}
\hline Role & $\begin{array}{c}\text { Mean } \\
\text { in-degree } \\
2017 \mid 2019\end{array}$ & $\begin{array}{c}\text { Mean } \\
\text { outdegree } \\
2017 \mid 2019\end{array}$ & $\begin{array}{c}\text { \# modularity } \\
\text { classes } \\
2017 \mid 2019\end{array}$ & $\begin{array}{c}\text { Eigenvector } \\
\text { centrality } \\
2017 \mid 2019\end{array}$ & $\begin{array}{c}\text { Betweenness- } \\
\text { centrality } \\
2017 \mid 2019\end{array}$ \\
\hline Journalist & $3.136 \mid 132$ & $4 \mid 1$ & $17 \mid 26$ & $0.0643 \mid 0.0119$ & $24,177 \mid 416$ \\
\hline Celebrity & $2.390 \mid 283$ & $3 \mid 1$ & $21 \mid 15$ & $0.0490 \mid 0.0254$ & $18,612 \mid 0$ \\
\hline $\begin{array}{l}\text { International } \\
\text { Organization }\end{array}$ & $2.124 \mid 398$ & $3 \mid 0$ & $1 \mid 2$ & $0.0440 \mid 0.0355$ & $98.702 \mid 0$ \\
\hline Social Bot & $1.950 \mid \mathrm{NA}$ & $3 \mid \mathrm{NA}$ & $5 \mid \mathrm{NA}$ & $0.0269 \mid \mathrm{NA}$ & $19,775 \mid \mathrm{NA}$ \\
\hline Media Organization & $1.285 \mid 95$ & $1 \mid 1$ & $13 \mid 24$ & $0.0265 \mid 0.0087$ & $23,858 \mid 511$ \\
\hline $\mathrm{NGO}$ & $1.235 \mid 554$ & $3 \mid 4$ & $7 \mid 15$ & $0.0255 \mid 0.0501$ & \begin{tabular}{l|l}
0 & 1,917
\end{tabular} \\
\hline Private Person & $1.110 \mid 121$ & $4 \mid 1$ & $24 \mid 49$ & $0.0228 \mid 0.0109$ & $5,552 \mid 1,171$ \\
\hline Politician & $1.086 \mid 124$ & $3 \mid 1$ & $4 \mid 2$ & $0.0223 \mid 0.0110$ & $0 \mid 48$ \\
\hline Company & $1.047 \mid 62$ & $0 \mid 1$ & $3 \mid 2$ & $0.0217 \mid 0,0056$ & $0 \mid 129$ \\
\hline Activist & $963 \mid 126$ & $3 \mid 4$ & $9 \mid 21$ & $\begin{array}{l}0.0199 \mid 0.0114 \\
\end{array}$ & $0 \mid 2,276$ \\
\hline Account deleted & $874 \mid 105$ & $1 \mid 5$ & $4 \mid 3$ & $0.0179 \mid 0.0094$ & $0 \mid 0$ \\
\hline $\begin{array}{l}\text { Governmental } \\
\text { Organization }\end{array}$ & $842 \mid 65$ & $3 \mid 1$ & $1 \mid 6$ & $0.0174 \mid 0.0559$ & $0 \mid 51$ \\
\hline $\begin{array}{l}\text { Religious } \\
\text { Organization }\end{array}$ & $826 \mid 46$ & $0 \mid 0$ & $1 \mid 1$ & $0.0169 \mid 0.0041$ & $0 \mid 0$ \\
\hline Account suspended & $624 \mid 95$ & $6 \mid 5$ & $13 \mid 3$ & $0.0129 \mid 0.0086$ & $34,693 \mid 45$ \\
\hline
\end{tabular}




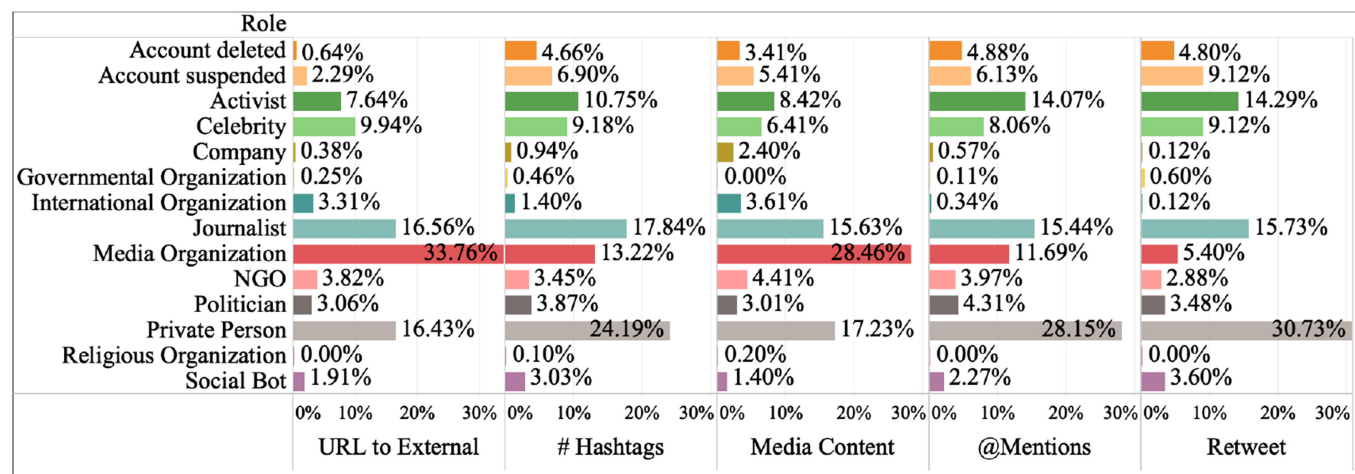

Fig. 2. Descriptive content metrics of top 300 power users (2017 dataset).

\begin{tabular}{|c|c|c|c|c|c|}
\hline $\begin{array}{r}\text { Role } \\
\end{array}$ & & & & & \\
\hline $\begin{array}{l}\text { Account deleted } \\
\text { Account suspended }\end{array}$ & $\begin{array}{l}1.01 \% \\
2.23 \%\end{array}$ & $\begin{array}{l}0.65 \% \\
3.57 \%\end{array}$ & $\begin{array}{l}0.00 \% \\
0.79 \%\end{array}$ & $\begin{array}{r}1.18 \% \\
3.66 \%\end{array}$ & $\begin{array}{l}0.24 \% \\
2.84 \%\end{array}$ \\
\hline Activist & $8.92 \%$ & $20.27 \%$ & $17.35 \%$ & $18.79 \%$ & $18.91 \%$ \\
\hline Celebrity & $7.91 \%$ & $4.43 \%$ & $7.57 \%$ & $3.55 \%$ & $3.07 \%$ \\
\hline Company & $2.03 \%$ & $0.65 \%$ & $0.00 \%$ & $0.00 \%$ & $0.00 \%$ \\
\hline Governmental Organi & $2.84 \%$ & $2.73 \%$ & $2.68 \%$ & $2.01 \%$ & $0.71 \%$ \\
\hline International Organization & $2.03 \%$ & $0.56 \%$ & $1.58 \%$ & $0.12 \%$ & $0.00 \%$ \\
\hline Journalist & & $7.85 \%$ & $9.78 \%$ & $8.04 \%$ & $10.87 \%$ \\
\hline $\begin{array}{r}\text { Media Organization } \\
\text { NGO }\end{array}$ & \begin{tabular}{|c|}
$13.79 \%$ \\
$17.85 \%$ \\
\end{tabular} & \begin{tabular}{|c|}
$8.15 \%$ \\
$12.57 \%$
\end{tabular} & \begin{tabular}{|c|}
$13.88 \%$ \\
$17.98 \%$ \\
\end{tabular} & $\begin{array}{l}7.68 \% \\
17.02 \%\end{array}$ & $3.55 \%{ }_{17.02 \%}$ \\
\hline Politician & | $1.01 \%$ & $0.56 \%$ & | $1.10 \%$ & $1.65 \%$ & $2.84 \%$ \\
\hline Private Person & $27.38 \%$ & $37.93 \%$ & $27.13 \%$ & $36.29 \%$ & \\
\hline Religious Organization & $0.41 \%$ & $0.06 \%$ & $0.16 \%$ & $0.00 \%$ & $0.00 \%$ \\
\hline & $0 \% \quad 10 \% \quad 20 \% \quad 30 \%$ & $0 \% \quad 10 \% \quad 20 \% \quad 30 \%$ & $0 \% \quad 10 \% \quad 20 \% \quad 30 \%$ & $\% 0 \% \quad 10 \% \quad 20 \% \quad 30 \%$ & $0 \% 10 \% \quad 20 \% \quad 30 \%$ \\
\hline & URL to External & \# Hashtags & Media Content & @Mentions & Retweet \\
\hline
\end{tabular}

Fig. 3. Descriptive content metrics of top 300 power users (2019 dataset).

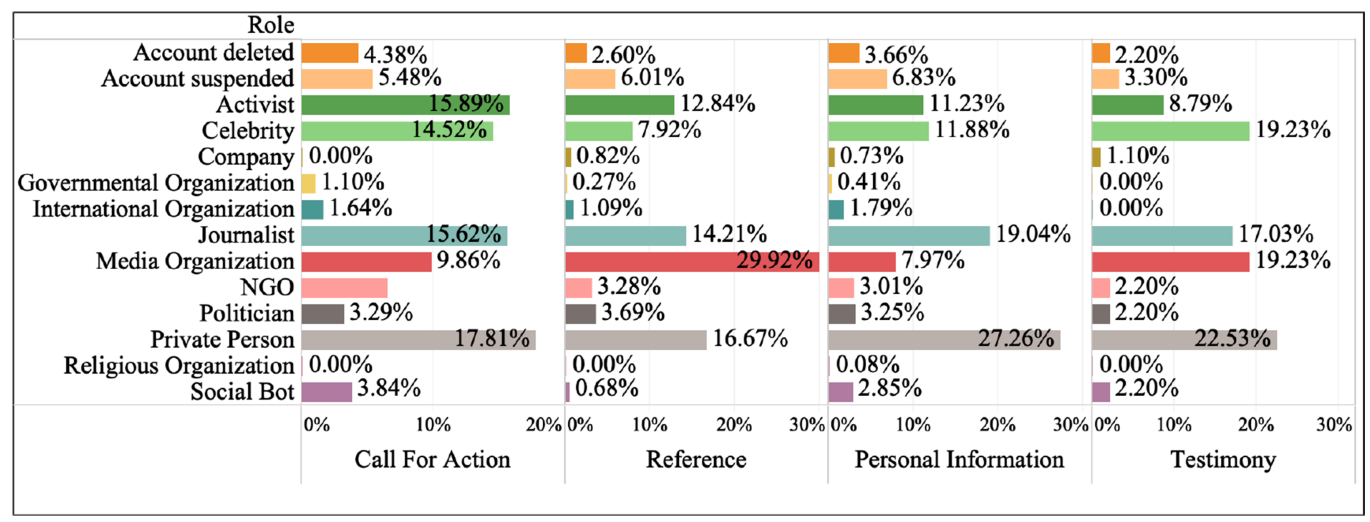

Fig. 4. Tweet content categories of top 300 power users (2017 dataset).

characteristics of the shared content. Second, we show the results considering the specific content of the shared tweets during the movement.

Figures 2-5 show the distribution of the assigned roles identified in the extracted sample for each descriptive and content category. The most represented roles in the descriptive and content categories are Media Organization, Journalist, and Private Person, as well as Celebrity and Activist. 


\begin{tabular}{|c|c|c|c|c|}
\hline Role & & & & \\
\hline Account deleted & $0.48 \%$ & $0.56 \%$ & $10.71 \%$ & $0.00 \%$ \\
\hline Account suspended & $0.00 \%$ & $1.54 \%$ & $3.54 \%$ & $0.00 \%$ \\
\hline Activist & $23.75 \%$ & $10.92 \%$ & $13.73 \%$ & $11.93 \%$ \\
\hline Celebrity & $3.80 \%$ & $6.58 \%$ & $5.93 \%$ & $6.42 \%$ \\
\hline & $0.24 \%$ & $\begin{array}{l}1.40 \% \\
336 \%\end{array}$ & $10.89 \%$ & $0.00 \%$ \\
\hline $\begin{array}{l}\text { Governmental Organization } \\
\text { International Organization }\end{array}$ & $0.00 \%$ & $1.40 \%$ & $\begin{array}{l}1.95 \% \\
0.89 \%\end{array}$ & $0.00 \%$ \\
\hline Journalist & $11.88 \%$ & $12.61 \%$ & $13.37 \%$ & $10.09 \%$ \\
\hline NGO & $24.23 \%$ & $16.67 \%$ & $11.43 \%$ & $25.69 \%$ \\
\hline Politician & $0.71 \%$ & $1.54 \%$ & $0.97 \%$ & $2.75 \%$ \\
\hline Private Person & $26.84 \%$ & $24.93 \%$ & $37.73 \%$ & $32.11 \%$ \\
\hline Religious Organization & $0.48 \%$ & $0.28 \%$ & $0.00 \%$ & $0.00 \%$ \\
\hline & $0 \% \quad 10 \% \quad 20 \% \quad 30 \%$ & $0 \% \quad 10 \% \quad 20 \% \quad 30 \%$ & $0 \% 10 \% \quad 20 \% \quad 30 \%$ & $0 \% 10 \% \quad 20 \% \quad 30 \%$ \\
\hline & Call For Action & Reference & Personal Information & Testimony \\
\hline
\end{tabular}

Fig. 5. Tweet content categories of top 300 power users (2019 dataset).

The role of Private Person leads all the descriptive categories in the dataset of 2019. Likewise, Private Person leads the "Number of Hashtags," “@mentions," and "retweet” descriptive categories in the dataset of 2017. However, in this dataset, the role of Media Organization takes the lead for the "URL to External Source" descriptive category as well as for that of "Media Content."

Regarding the tweet content categories, the role of Media Organization is revealed as the leading role in the "Reference" category for the 2017 dataset. Besides, the role of Private Person is the most represented in both datasets among the other tweet content categories. However, comparing both datasets shows that the role of Social Bot could not be detected for the 2019 dataset, and in addition, the role of NGO gains a bigger proportion. Furthermore, the role of Activist seems to be more strongly represented in the tweet content categories of the 2019 dataset, and Celebrities, as well as Media Organizations, see a decrease in their proportions.

Table 4 shows an overview of the results of the sentiment analysis. For each dataset, the polarity and the total sentiment load of a tweet is displayed. According to Stieglitz and Dang-Xuan [46], the polarity score (polarity = positive score + negative score) of a tweet describes whether a tweet tends to be more positive or negative on a textual level. Besides that, the total sentiment score (total sentiment $=($ positive score - negative score $)-2)$ presents the degree of the emotional loading of a tweet, independently from the negative or positive weighting. On average, the identified roles talk mainly negatively about \#metoo-related topics on Twitter. Only the role of Governmental Organization changed from an average negative polarity to a positive degree. The roles of Celebrity, Private Person, Politician, and NGO are the roles with the highest total sentiment on average. Overall, the average total sentiment degree of the roles increased from 2017 to 2019.

The results of the two regression analyses revealed that the predictive power of single variables changed. For the first dataset, we found that the "retweet" category significantly increased the likelihood that a tweet was retweeted as well as the categories "@mention," "call for action," "testimony," "sharing of personal opinion," and "negative sentiment." In contrast to that, we found that including media or a reference into a tweet decreased the number of retweets significantly (see Table 5). In addition, none of the identified roles was more or less likely to be retweeted.

Scrutinizing the results for the second dataset, the picture was different. We found that "Media Use" and "Testimony" positively influenced the number of retweets. This meant for the retweeting behavior that tweets that contained any picture or video and tweets that contained a testimony were more likely to be retweeted. Negatively significant were the "Number of Hashtags," "@Mention," and "Word count" variables, indicating that tweets with more hashtags and tweets that contained an @mention were less likely to be retweeted. In addition, we found that, other than for the first dataset, some roles were more likely to receive retweets than others. We found that the 
Table 4. Sentiment Analysis Results

\begin{tabular}{|l|c|c|c|c|}
\hline & \multicolumn{2}{|c|}{ 2017 Dataset } & \multicolumn{2}{c|}{ 2019 Dataset } \\
\hline Role & Avg. Polarity & Avg. Total Sentiment & Avg. Polarity & Avg. Total Sentiment \\
\hline Account deleted & -0.173 & 0.280 & 0.067 & 0.467 \\
\hline Account suspended & -0.172 & 0.336 & -0.339 & 0.597 \\
\hline Activist & -0.100 & 0.258 & -0.264 & 0.592 \\
\hline Celebrity & -0.272 & 0.512 & -0.410 & 0.564 \\
\hline Company & -0.214 & 0.214 & 0.094 & 0.200 \\
\hline $\begin{array}{l}\text { Governmental } \\
\text { Organization }\end{array}$ & -0.333 & 0.333 & 0.000 & 0.000 \\
\hline $\begin{array}{l}\text { International } \\
\text { Organization }\end{array}$ & -0.033 & 0.100 & -0.117 & 0.534 \\
\hline Journalist & -0.179 & 0.298 & -0.227 & 0.411 \\
\hline $\begin{array}{l}\text { Media } \\
\text { Organization }\end{array}$ & -0.167 & 0.347 & & 0.505 \\
\hline NGO & -0.260 & 0.369 & -0.176 & 0.647 \\
\hline Politician & -0.082 & 0.311 & -0.353 & 0.615 \\
\hline Private Person & -0.229 & 0.401 & 0.000 & 0.000 \\
\hline $\begin{array}{l}\text { Religious } \\
\text { Organization }\end{array}$ & 0.000 & 0.000 & NA & NA \\
\hline Social Bot & 0.000 & 0.379 & & \\
\hline
\end{tabular}

Table 5. Results of the Regression for the 2017 and 2019 Dataset

\begin{tabular}{|l|c|c|c|c|c|c|}
\hline & \multicolumn{3}{|c|}{ 2017 Dataset } & \multicolumn{3}{c|}{ 2019 Dataset } \\
\hline & $b$ & $S E$ & $p$ & $b$ & $S E$ & $p$ \\
\hline Number of hashtags & -0.16 & 0.03 & $<.0001$ & -0.11 & 0.02 & $<.0001$ \\
\hline URL use & -0.03 & 0.08 & .71 & 0.21 & 0.11 & .06 \\
\hline Media use & -0.18 & 0.09 & .04 & 0.26 & 0.11 & .02 \\
\hline Retweet & 0.89 & 0.09 & $<.0001$ & 0.18 & 0.13 & .16 \\
\hline @mention & 0.28 & 0.08 & .001 & -0.76 & 0.11 & $<.0001$ \\
\hline Call for action & 0.43 & 0.1 & $<.0001$ & -0.04 & 0.01 & .72 \\
\hline Testimony & 0.69 & 0.13 & $<.0001$ & 0.35 & .18 & .05 \\
\hline Sharing of personal opinion & 0.27 & 0.09 & .003 & 0.09 & 0.13 & .48 \\
\hline Reference & -0.25 & 0.09 & .005 & -0.04 & 0.12 & .7 \\
\hline Positive sentiment & 0.003 & 0.12 & .98 & -0.001 & 0.11 & .99 \\
\hline Negative sentiment & 0.22 & 0.05 & $<.0001$ & -0.005 & 0.06 & .92 \\
\hline Word count & -0.01 & 0.01 & .09 & 0.03 & 0.005 & $<.0001$ \\
\hline
\end{tabular}

roles "Celebrity" ( $b=1.58, S E=0.51, p=.002)$ and "Private Person" $(b=1.04, S E=0.49, p=.03)$ were significantly more likely to be retweeted. In contrast to that, if a company tweeted, it was less likely to receive retweets $(b=-2.87, S E=0.75, p=.0001)$. Implications of this are discussed below.

Figures 6 and 7 show the dynamics of Twitter communication during the \#metoo debate of the examined time periods. For the dataset of 2017, the first peak of communication in all four content categories can be observed on October 15, 2017, the day when the \#metoo hashtag went viral. The second peak can be found in mid-November, 2017, which we connected to 


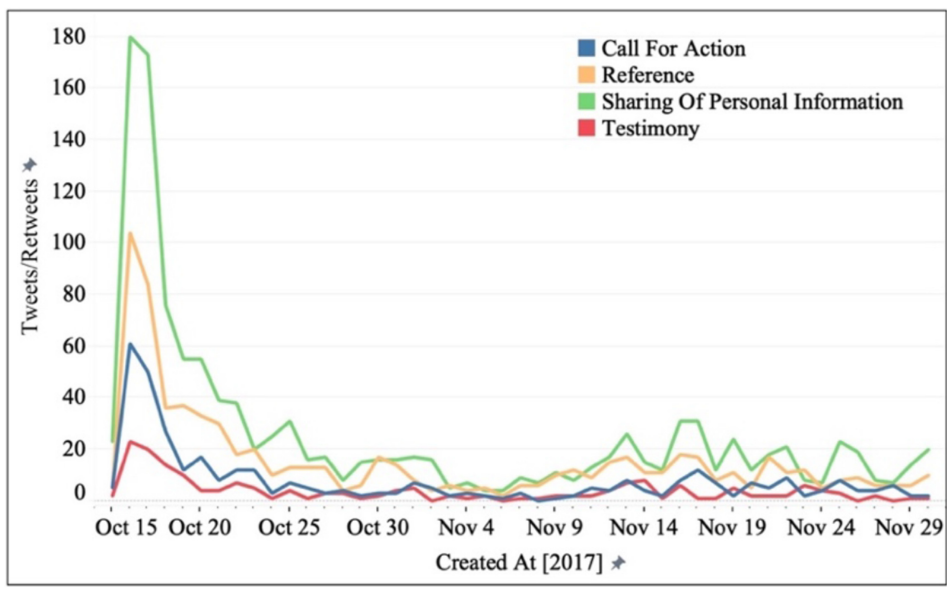

Fig. 6. Dynamics of the tweet content categories over time (2017 dataset).

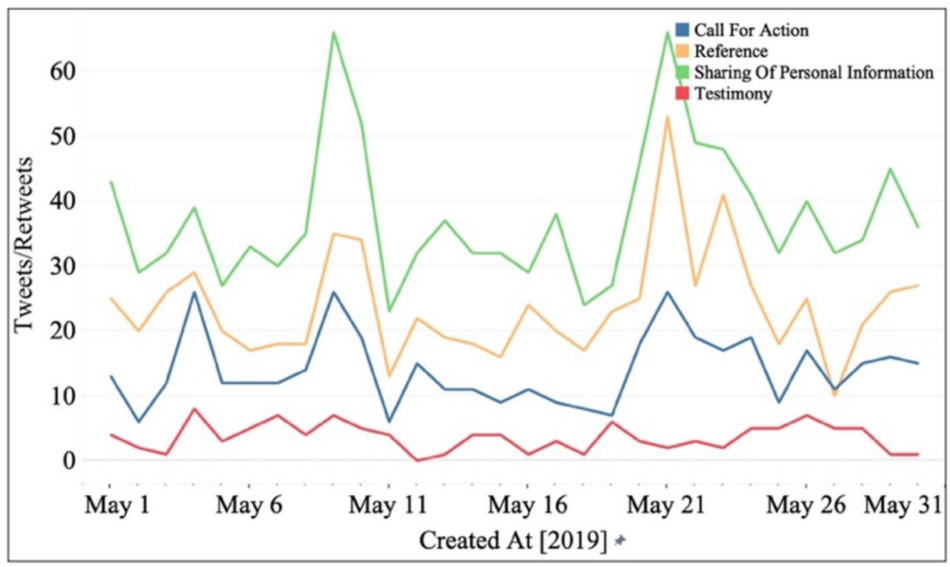

Fig. 7. Dynamics of the tweet content categories over time (2019 dataset).

several offline events, for example, the \#metoo survivor's march on November 12 and New York Senator Kirsten Gillibrand publicly referring to the \#metoo movement when discussing sexual harassment by known politicians on November 16. Moreover, regarding the specific categories, the category of "Sharing of Personal Information" is the leading category regarding the top 300 power users of the first dataset, followed by tweets that refer to other information and call for specificaction.

The analysis of the dynamics of the content categories of the 2019 dataset showed a similar distribution of the content categories shared in relation to the data from 2017. However, a clear amplitude, such as on the day when the movement went viral in 2017, was not observable. Moreover, two smaller increases in Twitter communication could be detected around May 10 and May 12. These might be connected to the media agenda, which revealed new information in the context of \#metoo. In summary, examining the evolving dynamics showed that the communication peaks of the distinct content categories were overall coherent. However, the strength of the amplitudes of each category is still different. 


\section{DISCUSSION}

\subsection{Participating Roles in Social Movements on Twitter}

This study provides findings regarding influential actors, defined as power users [38, 49], and their communication patterns during the \#metoo social movement on Twitter. According to Stieglitz et al. [49], the tweets of power users might have a higher informational value and are more likely to be considered during individuals' opinion formation. Thus, we identified 12 distinct influential roles participating in the social movement. These roles received the most retweets during the event, thereby shaping a large part of the communicational agenda. By analyzing the top 300 power users of each dataset, we covered accounts that led the \#metoo communication on Twitter, with several thousand retweets, as well as accounts that may have influenced smaller personal networks with a two-digit retweet count.

Our findings point to the roles of Private Person (22.66\% (2017), 35.54\% (2019)), Journalist (16.68\% (2017), 11.14\% (2019)), Media Organization (17.03\% (2017), 9.64\% (2019)), and Activist (11.35\% (2017), $13.74 \%$ (2019)) as some of the most influential roles during the \#metoo debate. This is mostly in line with prior results examining social movements like Occupy Wall Street, Indignados, and Aganaktismenoi [52].

However, we noticed that one user group, namely the role of Celebrity (10.41\% (2017), 5.33\% (2019)), diverged from the findings of Theocharis [52]. We explained this finding with the origin of the \#metoo debate as it was initiated by a celebrity. The decrease in 2019 supports this. Yet, it is also in line with previous findings showing that high status individuals are more likely to be retweeted [8], and the base rate probability might be connected to the follower count (celebrities were the most followed group of users on Twitter in 2017; Stieglitz et al. 2017). Furthermore, the roles of Media Organization and Journalist contributed smaller percentages in 2019, which might be explained by the lower importance attributed to the \#metoo debate in 2019 in the media.

The analysis of the findings reveals that Private Persons maintain the \#metoo debate on Twitter. Particularly in the 2019 dataset, it becomes apparent that Private Person is the most representative role and, therefore, essential for the ongoing movement.

Regarding the theory of connective action, it is shown that Twitter provides the infrastructure for those interpersonal networks that became visible. The results show that the main objective of Private Persons is to utilize the platform to express and connect themselves, which is line with similar research $[4,5]$. Next to roles such as Celebrity, Media Organization, and Journalist, which catalyze the movement in the first place, the findings suggest that the roles of Private Person and Activist are crucial for stable long-term communication. This might be explained by the distinct (personal) motivations of the roles.

As a special role, Social Bots, which have been found to influence conversations on Twitter before [44], were less represented in our analysis (2.89\% (2017), 0\% (2019)) but more so than companies $(0.70 \%$ (2017), 0.68\% (2019)). Both roles were less associated with the specific movement but might have infiltrated \#metoo-related communication on Twitter by using distinct hashtags to profit from the increased attention by referring to their own profiles or external commercial

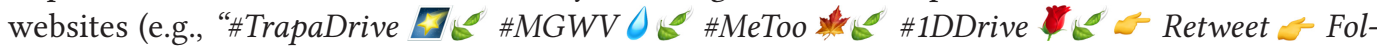

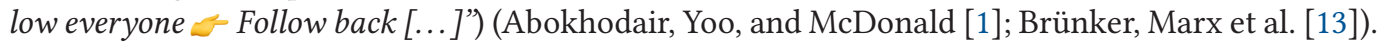
However, it might not have been worth Social Bots' distributers highjacking the \#metoo communication in 2019, which could be explained by less societal interest two years after \#metoo went viral.

The roles of Politician (3.09\% (2017), 1.16\% (2019)), International Organization (1.49\% (2017), $0.68 \%(2019))$, and Governmental Organization (0.30\% (2017), $2.19 \%(2019))$ contributed less to the debate on Twitter about \#metoo. Previous studies have shown similar results regarding these roles [52]. Regarding the role of NGO, our findings confirm the research of Theocharis [52] for the 2017 
dataset (3.64\%). However, observing the social movement over a period of two years reveals that NGOs (14.49\%) substantially gain relevance in the context of \#metoo-related Twitter communication. The theory of connective action suggests that NGOs may not have formal organization after the sudden outbreak of the debate in 2017. However, over the years this missing aspect may have formed, and the role of NGO grew in relevance. This implies that it is not sufficient to only analyze social movements that can be characterized according to the theory of connective action over a small period of time. To fully understand the formation of connective actions in the context of social movements, it is crucial to analyze long-term communication related to the movement.

\subsection{Dynamics of Roles Participating in Social Movements on Twitter}

Concerning the sharing of content, we revealed underlying differences between the identified roles. Addressing this, we provide new insights into the participating roles and the type of content that drove the discussion on Twitter at its outbreak and two years later.

According to the findings of the regression analyses, the use of hashtags, which has previously been found to increase the number of retweets [50], was negatively significant in both datasets, indicating the opposite: that the use of more hashtags actually decreased the likelihood of being retweeted. One explanation for this contradictory finding could be that hashtags were used by individuals with fewer followers and, therefore, had restricted reach with the goal of generating more attention. Furthermore, people may perceive a tweet with a high number of hashtags as being overloaded and, thus, less relevant. Likewise in the second dataset, the findings suggest that the use of @mentions was also associated with a decreased likelihood of being retweeted. We propose that a heavy use of @mentions could have been perceived as attention seeking. Previous research found that tweets expressing emotions were more likely to be shared $[10,46]$. However, our findings only partially support this research in the context of the \#metoo social movement. We found that negative sentiment received more retweets only in the first dataset.

Furthermore, while in the first dataset, the word count of tweets was irrelevant, in the second dataset longer tweets were more likely to be retweeted. This might be related to the characteristics of the two different time periods. We suggest that in the first time period in 2017, short, attentiongrabbing tweets were more attractive in terms of being retweeted, while in the second time period, more explicit and elaborate cases became attractive. Moreover, we found that in the first time period all content categories (call for action, testimony, sharing of personal opinion and references) increased retweet likelihood. However, for the second time period, we found that only testimonies and media content increased the likelihood of being retweeted, which supports our hypothesis that different sharing motives drove the retweeting process for the two time periods.

Regarding the change in the content shared by the distinct roles, it was revealed that Journalists were more active in the first dataset, particularly in the categories of "Sharing Personal Information" and "Testimony." In this way, Journalists act similarly to Private Persons. However, considering the findings of previous studies, our results from the 2017 dataset complement these well. Molyneux [37] revealed that journalists made use of personal, humoristic messages. The author explained this behavior as brand building, "driven more by a desire to form relationships with their audience than by journalists' work in information gathering" [37:932]. Thus, this behavior seems linked to the novelty of the event. This is supported by the findings of the 2019 dataset, which show that Journalists as well as Media Organizations were less active in all four content categories than in 2017. Tweeting about the movement two years later may not have the same worth than at the beginning of the event, in the context of informing the public as well as forming their own brands. The same behavior can be observed for the role of Celebrity, which highly supported the movement in the first dataset by posting content related to the "Testimony" and "Call for Action" categories. Considering the character of the initial tweet, a testimony and 
a call for action, other celebrities followed, sparking even more tweets. This points to similar findings to those of Alatas et al. [2], who found that celebrities hold an important role within social media-driven social movements, namely drawing attention to issues. The strong influence of Alyssa Milano's initial tweet underlines this claim. This also fits well with Castells' [15] idea of emotional mobilization, which is said, among the psychological states of a collection of individuals, to be essential for starting a social movement. The wording of Milano's tweet contained both the necessary outrage and the hope for possible change.

Comparing the first 200 power users with the following 100 power users in the retweet ranking, our results reveal that Private Persons were particularly active in the lower retweet rankings of power users [14]. This suggests that Private Persons might not be that popular in getting retweeted compared to, for example, Celebrities. However, the results from 2019 show that Private Persons maintain the \#metoo debate on Twitter for all content categories, in particular, for "Testimony" and "Sharing Personal Information." The theory of connective action explains that roles such as Private Person or Activist use Twitter to help bring their objectives into the public eye in a non-organized way.

Moreover, we see reasons to believe that, although financial and technical costs are lower when using social media communication [56], psychological costs remain high. The benefits of disclosing personal information, especially highly stigmatized information such as sexual harassment, on the Internet must outweigh its risks. Again, we can only suggest possible explanations for our observations, but it is likely that either disclosing costs of Celebrities and Journalists were lower at the beginning of the social movement or disclosing gains of Celebrities and Journalists were higher. This points again to a possible branding motive. Overall, it seems to be less worthwhile for roles such as Celebrity, Journalist, or Media Organization to participate in the \#metoo debate two years later. These roles may have motives other than those of the roles of Private Person, Activist, and NGO. Summarizing our results, we found that the behavior of Private Persons, NGOs, and Activists is related to maintaining the social movement in the long term, whereas Media Organizations, Celebrities, and Journalists provide information about the movement as well as using the attention to form their own brands.

\subsection{Reflecting Roles in Connective Action}

The theory of connective action explains how loosely connected actors engage in digitally networked action [5]. We first provide insights into how self-motivated roles contribute to connective action on social media in the context of social movements. Besides self-produced content that is shared and recognized by other participants [5], the \#metoo social movement, at its beginning in 2017, was characterized by content created by Media Organizations, Journalists, and Celebrities. These roles are most retweeted during the start of the movement on Twitter. In particular, Media Organizations and Journalists are characterized by a decent degree of formal organization to disseminate their content and information. Besides the aim of providing trustworthy information to the public, these roles are also led by economical goals. Likewise, the role of Celebrity was the main reason why \#metoo went viral. However, the data showed that a variety of Celebrities and Journalists might have used the \#metoo debate for personal branding on social media.

Summarizing, these roles can be characterized as connective action starters in the context of social movements. However, analyzing the \#metoo debate two years after it went viral revealed that the roles associated with connective action starters lost percentages. Moreover, the roles of Private Person, NGO, and Activist grew. Above all, Private Persons and NGOs provided information related to the categories of "Sharing Personal Information," "Call for Action," and "Testimony." The role of NGO mainly shared content related to the "Testimony" and "Call for Action" categories, and Activists were most active in distributing calls for action. These findings suggest that the roles 


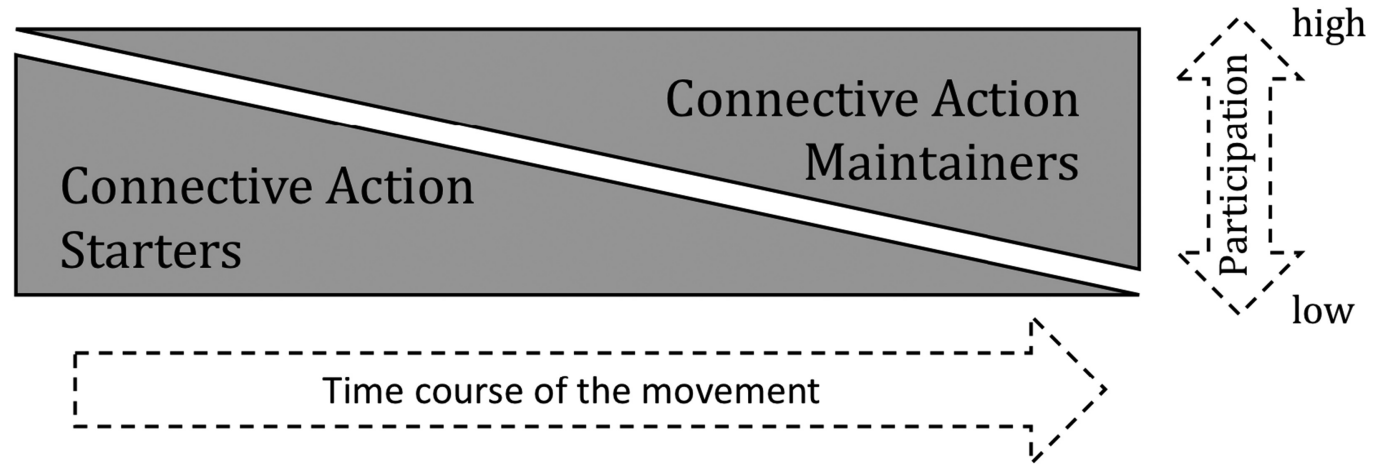

Fig. 8. Participation of connective action starters and maintainers.

of Private Person, NGO, and Activist can be characterized as connective action maintainers (see Figure 8). In the context of connective action and social movements, these maintainers are crucial for stable long-term communication and participation. Particularly noteworthy is the role of Private Person, which acts as a connector in both datasets. They might not be the most retweeted actors, but they are important for wide-spread information diffusion in loosely connected networks on social media.

\section{CONCLUSION AND OUTLOOK}

In our study, we investigated how specific roles participate over the course of the \#metoo debate (RQ1) and how these roles contributed to connective action (RQ2). We found different roles, like Journalists, Media Organizations, and Celebrities, but also Private Persons and Activists, who drove the spread of \#metoo in their own ways. Thus, we derived the types of connective action starters and maintainers from the findings and the literature. Moreover, by investigating the content shared by each group, we found substantial differences. The results point to different motives when sharing content via Twitter, from self-serving and branding intentions to goals that actually draw attention and action toward the cause of sexual harassment.

This study contributes to knowledge by identifying distinct influential roles during a social movement that evolve mainly online. This step is necessary to understand the differences between social movements evolving online and offline. We contribute to the understanding of connective action theory by reflecting on the identified roles and introducing two archetypes of connective action roles: starters and maintainers. The findings will help future research to examine the theory of connective action in further movements in a more fine-grained way.

Furthermore, using two new datasets, first, indicators for key actors and their behaviors over the course of a movement were examined, for example, the amount of contribution from a specific role at a certain point in the movement. Likewise, the findings also outline practical implications. For example, the most popular shareable content was "Sharing of Personal Information." Thus, this finding could help several stakeholders, such as social activists or NGOs, to better organize and, therefore, promote their agendas.

This study also faced several limitations. The content categories were comparatively broad as the material was highly heterogenous. However, by merging the roles based on their behavior into two overarching connective action types, we took a first step toward decreasing the complexity of an online social movement. Additionally, the results are based on the case of \#metoo. We encourage future research to reproduce the study using another case. 
Moreover, we suggest research that focuses on connective action starters or maintainers with a more fine-grained analysis that could reveal underlying differences in a more differentiated way. To this end, a comprehensive analysis of personal networks that dynamically evolve over the course of a movement may reveal insights into the development of specific roles. Moreover, further research may focus on investigating individuals' specific motives by survey people and compare their social media behavior. Our findings may function as a foundation for further research on social movements and the theory of connective action.

\section{REFERENCES}

[1] Norah Abokhodair, Daisy Yoo, and David W. McDonald. 2015. Dissecting a social botnet: Growth, content and influence in twitter. In Proceedings of the 18th ACM Conference on Computer Supported Cooperative Work \& Social Computing. 839-851.

[2] Vivi Alatas, Arun G. Chandrasekhar, Markus Mobius, Benjamin A. Olken, and Cindy Paladines. 2019. When Celebrities Speak: A Nationwide Twitter Experiment Promoting Vaccination in Indonesia. Cambridge, MA.

[3] Manaf Bashir. 2012. Framing an Online Social Movement: How Do the Leadership and Participants of the Egyptian 6th of April Youth Movement Frame their Facebook Activism? Indiana university. Retrieved from www.i-r-i-e-net.

[4] Y. Benkler. 2016. Peer production and cooperation. In Handbook on the Economics of the Internet. Edward Elger Publishing, Cheltenham, UK. DOI : https://doi.org/doi.org/10.4337/9780857939852.00012

[5] W. Lance Bennett and Alexandra Segerberg. 2012. The logic of connective action: Digital media and the personalization of contentious politics. Inf. Commun. Soc. 15, 5 (2012), 739-768. DOI : https://doi.org/10.1080/1369118X.2012. 670661

[6] B. Bimber, A. J. Flanagin, and Cynthia Stohl. 2005. Reconceptualizing collective action in the contemporary media environment. Commun. Theory 15, 4 (2005), 365-388.

[7] Y. Bonilla and J. Rosa. 2015. \#Ferguson: Digital protest, hashtag ethnography, and the racial politics of social media in the united states. Am. Ethnol 42, 1 (2015), 4-17. DOI : https://doi.org/https://doi.org/10.1111/amet.12112

[8] Danah Boyd, Scott Golder, and Gilad Lotan. 2010. Tweet, tweet, retweet: Conversational aspects of retweeting on twitter BT. In Proceedings of the Annual Hawaii International Conference on System Sciences. 1-10.

[9] Florian Brachten, Milad Mirbabaie, Stefan Stieglitz, Olivia Berger, Sarah Bludau, and Kristina Schrickel. 2018. Threat or opportunity? Examining social bots in social media crisis communication. In Proceeedings of the Australasian Conference on Information Systems.

[10] William J. Brady, Julian A. Wills, John T. Jost, Joshua A. Tucker, and Jay J. Van Bavel. 2017. Emotion shapes the diffusion of moralized content in social networks. Proceedings of the National Academy of Sciences 114, 28 (2017), 7313-18. DOI : https://doi.org/10.1073/pnas.1618923114

[11] Ulrike Brandes. 2001. A faster algorithm for betweenness centrality. F. Math. Sociol. 25, 2 (2001), 163-177.

[12] Felix Brünker, Fabian Deitelhoff, and Milad Mirbabaie. 2019. Collective identity formation on instagram-investigating the social movement fridays for future. In Australasian Conference on Information Systems. Perth, Western Australia, 304-310.

[13] Felix Brünker, Julian Marx, Milad Mirbabaie, and Stefan Stieglitz. 2020. 'The tireless selling-machine ' - commercial deployment of social bots during black friday season on twitter. In Proceedings of the 15th International Conference on Wirtschaftsinformatik.

[14] Felix Brünker, Magdalena Wischnewski, Milad Mirbabaie, and Judith Meinert. 2020. The role of social media during social movements-Observations from the \#metoo debate on twitter. In Proceedings of the 53rd Hawaii International Conference on System Sciences. 2356-2365. DOI: https://doi.org/10.24251/hicss.2020.288

[15] M. Castells. 2015. Networks of Outrage and Hope: Social Movements in the Internet Age. John Wiley \& Sons.

[16] Camilo Cristancho and Eva Anduiza. 2013. Connective action in european mass protest. In Social Media and Political Participation.

[17] E. DeMarrais and T. Earle. 2017. Collective action theory and the dynamics of complex societies. Annu. Rev. Anthropol 46, 1 (2017), 183-201.

[18] L. R. Diaz Cepeda. 2015. \#Yosoy132: A networked social movement of mexican youth. In Waves of Social Movement Mobilizations in the Twenty-First Century. Challenges to the Neo-Liberal World Order and Democracy, N. Konak and R. Özgür (Eds.). Lexington Books, New York, 41-84.

[19] José Van Dijck and Thomas Poell. 2013. Understanding social media logic. Media Commun. 1, 1 (2013), 2-14. DOI : https: //doi.org/10.12924/mac2013.01010002

[20] C. Ehnis, M. Mirbabaie, D. Bunker, and S. Stieglitz. 2014. The role of social media network participants in extreme events. In Proceedings of the 25th Australian Conference on Information Systems (2014). 
[21] Amanda Erickson. 2018. In 2018, \#MeToo-and its backlash-went global. The Washington Post. Retrieved March 15, 2019 from https://www.washingtonpost.com/world/2018/12/14/metoo-its-backlash-went-global/?noredirect= on\&utm_term=.2bc1530daaf1.

[22] M. J. Jensen and H. P. Bang. 2013. Occupy wall street: A new political form of movement and community? f. Inf. Technol. Polit. 10, 4 (2013), 444-461.

[23] Jodi Kantor and Megan Twohey. 2017. Harvey weinstein paid off sexual harassment accusers for decades. The New York Times. Retrieved March 29, 2019 from https://www.nytimes.com/2017/10/05/us/harvey-weinstein-harassmentallegations.html.

[24] Anastasia Kavada. 2015. Creating the collective: Social media, the occupy movement and its constitution as a collective actor constitution as a collective actor. Inf. Commun. Soc. 18, 8 (2015), 872-886. DOI : https://doi.org/10.1080/1369118X. 2015.1043318

[25] Dustin Kidd and Keith Mcintosh. 2016. Social media and social movements. Sociol. Compass 10/9, (2016), $785-794$. DOI : https://doi.org/10.1111/soc4.12399

[26] Klaus Krippendorff and Andrew F. Hayes. 2007. Answering the call for a standard reliability measure for coding data. Commun. Methods Meas. 1, 1 (2007), 77-89.

[27] Carmen Leong, Shan L. Pan, Shamshul Bahri, and Ali Fauzi. 2018. Social media empowerment in social movements : Power activation and power accrual in digital activism. Eur. J. Inf. Syst. 28, 2 (2018), 1-32. DOI: https://doi.org/10. 1080/0960085X.2018.1512944

[28] Daniel Lundgaard and Liana Razmerita. 2016. Connective versus collective action in social movements: A study of co - creation of online communities. In Connected Life. Oxford, UK, 1-2.

[29] Lydia Manikonda, Ghazaleh Beigi, Huan Liu, and Subbarao Kambhampati. 2018. Twitter for sparking a movement, reddit for sharing the moment: \# metoo through the lens of social media. In Proceedings of the 11th International Conference on Social Computing, Behavioral-Cultural Modeling \& Prediction and Behavior Representation in Modeling and Simulation (SBP-BRiMS'18). USA.

[30] Philipp Mayring. 2014. Qualitative Content Analysis: Theoretical Foundation, Basic Procedures and Software Solution. Klagenfurt, Austria. DOI : https://doi.org/https://nbn-resolving.org/urn:nbn:de:0168-ssoar-395173

[31] David Meek. 2011. Youtube and social movements: A phenomenological analysis of participation, events and cyberplace. Antipode 44, 4 (2011), 1429-1448. DOI : https://doi.org/10.1111/j.1467-8330.2011.00942.x

[32] Judith Meinert, Milad Mirbabaie, Sebastian Dungs, and Ahmet Aker. 2018. "Is it really fake? - Towards an understanding of fake news in social media communication. In Proceedings of the 20th International Conference on HumanComputer Interaction, Social Computing and Social Media, Springer, 484-497.

[33] Milad Mirbabaie, Deborah Bunker, Stefan Stieglitz, Julian Marx, and Christian Ehnis. 2020. Social media in times of crisis: Learning from hurricane harvey for the coronavirus disease 2019 pandemic response. f. Inf. Technol. 35, 3 (2020), 195-213. DOI : https://doi.org/10.1177/0268396220929258

[34] Milad Mirbabaie, Christian Ehnis, Stefan Stieglitz, and Deborah Bunker. 2014. Communication roles in public events - A case study on twitter communication. In Information Systems and Global Assemblages: (Re)configuring Actors, Artefacts, Organizations: IFIP WG 8.2 Working Conference on Information Sysanizations. 207-218.

[35] Milad Mirbabaie and Julian Marx. 2019. 'Breaking' News: Uncovering sense-breaking patterns in social media crisis communication during the 2017 manchester bombing. Behav. Inf. Technol 39, 3 (2019).

[36] Milad Mirbabaie, Stefan Stieglitz, and Felix Brünker. 2021. Dynamics of convergence behaviour in social media crisis communication - a complexity perspective. (unpublished). DOI : https://doi.org/10.1108/ITP-10-2019-0537

[37] Logan Molyneux. 2015. What journalists retweet: Opinion, humor, and brand development on twitter. fournalism 16, 7 (2015), 920-935. DOI : https://doi.org/10.1177/1464884914550135

[38] Onook Oh, Chanyoung Eom, and H. R. Rao. 2015. Research note-Role of social media in social change: An analysis of collective sense making during the 2011 egypt revolution. Inf. Syst. Res. 26, 1 (2015), 210-223. DOI : https://doi.org/ $10.1287 /$ isre.2015.0565

[39] Onook Oh, Nargess Tashmasbi, Raghav H. Rao, and Gert-Jan Vreede. 2012. A sociotechnical vie of information diffusion and social changes: From reprint to retweet. In Proceedings of the International Conference on Information Systems.

[40] Mancur Olsen. 1971. The Logic of Collective Action. Havard University Press, Cambridge, MA.

[41] Mancur Olsen. 2009. The Logic of Collective Action: Public Goods and the Theory of Groups. Havard University Press, Cambridge, MA.

[42] E Ostrom. 2000. Collective action and the evolution of social norms. f. Econ. Perspect. 14, 3 (2000), 137-158.

[43] H. Rane and S. Salem. 2012. Social media, social movements and the diffusion of ideas in the arab uprisings. F. Int. Commun. 18, 1 (2012), 97-111.

[44] Björn Ross, Laura Pilz, Benjamin Cabrera, Florian Brachten, German Neubaum, and Stefan Stieglitz. 2019. Are social bots a real threat? An agent-based model of the spiral of silence to analyse the impact of manipulative actors in social networks. Eur. J. Inf. Syst. (2019). DOI : https://doi.org/10.1080/0960085X.2018.1560920 
[45] Stefan Stieglitz and Linh Dang-Xuan. 2012. Political communication and influence through microblogging - An empirical analysis of sentiment in twitter messages and retweet behavior. In Proceedings of the Annual Hawaii International Conference on System Sciences. 3500-3509. DOI : https://doi.org/10.1109/HICSS.2012.476

[46] Stefan Stieglitz and Linh Dang-Xuan. 2013. Emotions and information diffusion in social media sentiment of microblogs and sharing behavior. F. Manag. Inf. Syst. 29, 4 (2013), 217-247. DOI: https://doi.org/10.2753/MIS07421222290408

[47] Stefan Stieglitz, Milad Mirbabaie, and Maximilian Milde. 2018. Social positions and collective sense-making in crisis communication. Int. J. Hum. Comput. Interact. 34, 4 (2018), 328-355. DOI : https://doi.org/10.1080/10447318.2018. 1427830

[48] Stefan Stieglitz, Milad Mirbabaie, Björn Ross, and Christoph Neuberger. 2018. Social media analytics - challenges in topic discovery, data collection, and data preparation. Int. f. Inf. Manage. 39, (2018), 156-168. DOI : https://doi.org/10. 1016/j.ijinfomgt.2017.12.002

[49] Stefan Stieglitz, Milad Mirbabaie, Lara Schwenner, Julian Marx, Janina Lehr, and Felix Brünker. 2017. Sensemaking and communication roles in social media crisis communication. In Proceedings of the 13the Internationalen Tagung Wirtschaftsinformatik (WI'17). 1333-1347.

[50] Bongwon Suh, Lichan Hong, Peter Pirolli, Ed H. Chi, Palo Alto, and Palo Alto. 2010. Want to be retweeted? Large scale analytics on factors impacting retweet in twitter network. In Proceedings of the IEEE International Conference on Social Computing. 177-184. DOI : https://doi.org/10.1109/SocialCom.2010.33

[51] M. Thelwall, K Buckley, G. Paltoglou, D. Cai, and A. Kappas. 2010. Sentiment strength detection in short informal text mike. J. Am. Soc. Inf. Sci. Technol. 61, 12 (2010), 2544-2558. DOI : https://doi.org/10.1002/asi

[52] Yannis Theocharis. 2013. The wealth of ( occupation ) networks ? Communication patterns and information distribution in a twitter protest network. F. Inf. Technol. Polit. 10, 1 (2013), 35-56. DOI : https://doi.org/10.1080/19331681.2012. 701106

[53] Bridget Tombleson and Katharina Wolf. 2017. Rethinking the circuit of culture: How participatory culture has transformed cross-cultural communication. Publ. Relat. Rev. 43, 1 (2017), 14-25. DOI : https://doi.org/10.1016/j.pubrev.2016. 10.017

[54] Michelle Tye, Carmen Leong, Felix Ter Chian Tan, Barney Tan, and Ying Hooi Khoo. 2018. Social media for empowerment in social movements: The case of malaysia's grassroots activism. Commun. Assoc. Inf. Syst. 42, 1 (2018), 408-430 DOI : https://doi.org/10.17705/1CAIS.04215

[55] Ying Xiong, Moonhee Cho, and Brandon Boatwright. 2019. Hashtag activism and message frames among social movement organizations: Semantic network analysis and thematic analysis of twitter during the \#metoo movement. Publ. Relat. Rev. 45, 1 (2019), 10-23. DOI : https://doi.org/10.1016/j.pubrev.2018.10.014

[56] Serpil T. Yuce, Rolf T. Wigand, and Rebecca S. Robinson. 2013. Blogging, bridging, and brokering: Analyzing interconnected networks in online collective actions. In PACIS 2013 Proceedings. 225. DOI : https://doi.org/https://aisel. aisnet.org/pacis2013/225

Received January 2020; revised November 2020; accepted January 2021 